\title{
Research Paper: Comparing the Effect of the Two Educational Methods: Competency-Based, and Lecture, on the Knowledge and Performance of Nurses in the Field of Hospital Triage
}

\author{
Seied Davood Hoseini ${ }^{1}$, Hamid Reza Khankeh ${ }^{2 *}$, Asghar Dalvandi ${ }^{1}$, Amin Saberinia $^{3}$, Pouria Rezasoltani ${ }^{4}$, Seiedeh Zahra Mirzaeirad $^{5}$
}

1. Department of Nursing, University of Social Welfare and Rehabilitation Sciences, Tehran, Iran.

2. Department of Public Health Sciences, Karolinska Institutet, Stockholm, Sweden.

3. Department of Emergency Medicine, School of Medicine, Kerman University of Medical Sciences, Kerman, Iran.

4. Department of Biostatics, University of Social Welfare and Rehabilitation Sciences, Tehran, Iran.

5. Department of Nursing, School of Nursing \& Midwifery, Golestan University of Medical Sciences, Gorgan, Iran.

\begin{tabular}{|c|c|}
\hline $\begin{array}{l}\text { Use your device to scan } \\
\text { and read the article online }\end{array}$ & Citation: Hoseini SD, Khankeh HR, Dalvandi A, Saberinia A, Rezasoltani P, Mirzaeirad SZ. Comparing the Effect of the Two \\
\hline 回的回 & Educational Methods: Competency-Based, and Lecture, on the Knowledge and Performance of Nurses in the Field of Hospital \\
\hline 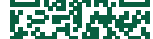 & Triage. Health in Emergencies and Disasters Quarterly. 2018; 3(2):77-84. https://doi.org/10.29252/NRIP.HDQ.3.2.77 \\
\hline ard & doli: : https://doi.org/10.29252/NRIP.HDQ.3.2.77 \\
\hline
\end{tabular}

Article info:

Received: 10 Jul. 2017

Accepted: 20 Oct. 2017

\section{Keywords:}

Triage, Competency-based education, Lecture, Nurse

\section{ABSTRACT}

Background: The most critical issue in providing appropriate services to the large number of patients referring to emergency wards is the proper conduct of triage, by considering the shortage of personnel and the insufficiency of facilities. The learning of the triage can only be possible through retraining of nurses. Therefore, this study attempts to compare the two educational methods, competency-based training and lecture, and to compare their impact on the knowledge and performance of nurses regarding triage.

Materials and Methods: In this semi-experimental study, 75 nurses employed in the emergency wards of Fatemeh Al-Zahra, Rasul Akram, and Shahid Motahari hospitals were selected based on the inclusion criteria of the study. Nurses were placed in three groups (one control and two intervention, $\mathrm{n}=25$ ) through a simple random method person groups of control and intervention. The researcher-made tools included "triage knowledge test" with 15 questions, and "triage performance checklist" that included 50 scores. The validity of the tests was performed through the formal and content method with the opinion of experts, and the reliability was verified through the test-retest method for which the Pearson Correlation Coefficient was 0.88. After examining the level of knowledge and performance, the intervention was carried out through two methods in the two groups. Eventually, a renewed test and the performance checklist were carried out for all the three groups and data were analyzed using SPSS software V. 21.

Results: There is a significant difference between the mean score for knowledge and performance in the two groups before and after intervention $(\mathrm{P}<0.05)$. Also, there was a significant difference between the two intervention groups and control in the mean difference of scores for knowledge and performance in conducting the triage $(\mathrm{P}<0.05)$. Comparison between the two intervention groups demonstrates that in the performance part, the competency-based group had a higher performance score $(\mathrm{P}<0.05)$.

Conclusion: Education and training through the competency-based method have more effect than lecture training on the performance of nurses in the field of triage. It is suggested to use this method for retraining of nurses in the field of triage.

\section{* Corresponding Author: \\ Hamid Reaza Khankeh, PhD}

Address: Department of Public Health Sciences, Karolinska Institutet, Stockholm, Sweden.

E-mail: hamid.khankeh@ki.se 


\section{Introduction}

ospitals have the primary role in establishing the right of the need for urgent care and timely treatment [1]. Under ordinary circumstances, the emergency ward has been increasingly considered by the general public as the entry point to the hospital [2]. Iran is prone to medical emergencies and accidents and is one of the most vulnerable countries in this regard [3]. Under such circumstances establishing the triage seems unavoidable. The purpose of triage is to prioritize the patients for the requirement of treatment up-front [4]. Results show that the knowledge and awareness of nurses about triage are insufficient [5-7]. The reality is, that in the academic curriculum there are no specific categories for teaching the triage and the only solution available is to organize training workshops and to refer to the very few and scattered articles that have been published in this field [8]. The lecture is one of the more common and traditional methods in Iran's medical community regarding the continuing education programs [9].

Kavoosi (2013) reported that retraining classes were usually held in the form of lecture, and studies have shown that $80 \%$ of nurses acquire information during retraining classes that are not suitable for the medical departments they work in, and $60 \%$ of nurses oppose the conduct of in-service training and retraining programs under that method. The non-standard implementation of these programs has led to a reduction of the nurses' competency in the clinical environments, and as a consequence, the quality of care the nurses provide to patients is declined [10].

Learning of fundamental issues in providing nursing care requires new educational strategies [11]. One of these methods is the competency-based education program that provides the personnel who require the general and specialized competencies to do their job and acquire them based on their competencies. The purpose of competency is to provide nursing care based on professional standards of performance, and competency-based retraining program provides the skills and capabilities needed by nurses for a safe and effective function without the need for direct supervision $[12,13]$. Apparently, the only study conducted in Iran on the competencybased education was reported by Kavoosi (2013) on the emergency ward nurses in the field of cardiopulmonary resuscitation that led to an upgrade of $40 \%$ in this regard [10]. As per out knowledge, this is the first report to make a comparison under this method. Considering the need for retraining in the field of triage and the use of new methods, this study proceeds to compare the lecture-based education and competency-based training and their effect on the knowledge and performance of nurses in the field of hospital triage.

\section{Materials and Methods}

This was a semi-experimental three group study. The research population included the nurses who were employed (winter 2016) at the emergency wards of Shahid Motahari Hospital, Gonbad Kavoos, Rasul Akram Hospital, Kalaleh and Fatemeh Al-Zahra Hospital, Minoodasht at the time the study was conducted. All the three hospitals are general hospital and located in the eastern part of the province of Golestan in northern Irans. About the number of beds and personnel these hospitals are almost similar and the three cities of Gonbad Kavoos, Kalaleh, and Minoodasht are similar regarding demographic and cultural contexts. The sampling method was the total population sampling method (non-randomized sampling based on willingness to take part in the study). All nurses who held at least a Bachelor's Degree were registered and were assigned a number. Twenty eight nurses were placed in the intervention groups, and 27 were placed in the evidence-based group.

In the competency-based intervention group, one nurse because of having had participated in a similar workshop and two nurses because they were not present in all of the stages of the research were excluded from the study, and eventually 25 nurses comprised the intervention group. In the lecture-based intervention group, three nurses were excluded from the study because they did not participate in the training workshop therefore, 25 nurses remained. In the control group two nurses because they were not present in all of the stages of the research were excluded from the study, and eventually, 25 nurses comprised the control group.

To collect data, a questionnaire containing 15 questions was prepared to determine the level of knowledge of nurses before the intervention and one month after the intervention and was responded by the study population. A checklist including nine main items and 50 scores (checklist of Alborz University of Medical Sciences approved by the Ministry of Health) was used to determine the performance level. Before the intervention and one month after the intervention, the checklist was filled by the researcher with the supervision of the educational supervisor of the hospitals. Verification of the validity of the questionnaire and the checklist was performed by 9 authorities from the University of Social Welfare and 
Rehabilitation Sciences (1 professor), officials of The National Organization for Emergencies at the Ministry of Health (5 officials) and emergency medicine specialists of Imam Khomeini Hospital of Tehran and the University of Tehran (3 specialists).

The validity of the test was performed through the method suggested by Lavashi, and all of the questions had required validity. The reliability of the test was performed using the test-retest method in a way that 10 members of the emergency ward's nursing personnel of Hazrat Ma'sumeh Hospital who were not participating in the research responded to the questionnaire within two weeks. The reliability of the test for all of the questions was calculated using the Pearson Correlation Coefficient, and the result was 0.99 which is acceptable and demonstrates the reliability of the tools. The collected data was analyzed by SPSS V. 21 and by Chi-square test, Fisher's Exact test, Kolmogorov Smirnov test, Wilcoxon test, One-Way Analysis of Variance, Tukey post hoc test, and Kruskal Wallis Test.

The intervention was carried out through a one-day lecture workshop in an intervention group and intradepartmental training and on the basis of competency in the other intervention group which included the following: 1. Holding an intradepartmental meeting and presenting educational materials from the hospital triage book; 2. Referring to records and files and questionnaire and checklist to identify weak and strong points; 3. Providing a flash card of the mistake of each personnel member to her individually, along with practicing the clinical instances; 4 . Weekly reflection meeting and presentation of the solution by the personnel for the existing situation; 5 . Providing the obtained results to the departmental director and the nursing management.

\section{Results}

Demographic variables were compared to examine the similarity of the two groups (Table 1). Table 2 indicates mean (SD) of the scores on knowledge received by the emergency ward nurses regarding hospital triage (before and after) and mean (SD) of performance of the emergency ward nurses regarding hospital triage (before and after) are shown in Table 3. The results of Table 4 show that after the test there is a significant difference between the mean scores of the emergency ward nurses regarding triage in three groups of evidence-based, the lecture intervention and the competency-based intervention $(\mathrm{P}<0.05)$.

A significant $(\mathrm{P}<0.05)$ difference between the mean scores of the knowledge of emergency ward nurses in the control group and the two intervention groups of lecture and competency-based was observed as determined by the Tukey test (Table 5). Therefore, it can be concluded that regarding the knowledge of nurses on triage, both of the lecture intervention group and competency-based intervention group were more effective as compared with the control group. Regarding the triage, no significant difference was observed between the mean scores on the knowledge of the emergency ward nurses in the lecture intervention group and the competency-based intervention group $(\mathrm{P}>0.05)$.

The results of Table 6 shows that there is a significant difference regarding the triage between the median rating of scores for the performance of the emergency ward nurses in the three groups of evidence-based, lecture intervention, and competency-based $(\mathrm{P}<0.05)$. Considering the observed significant difference between the median rating of the scores of the three study groups, it can be concluded that in the field of hospital triage, the competency-based intervention has a more significant impact on improving the performance of nurses regarding the hospital triage.

\section{Discussion}

Findings of this study demonstrate that before the study, the three groups had similar underlying variables. There is a significant difference between the knowledge and performance of nurses in both the intervention groups, before and after training, while in the control group, no significant difference was observed between the median scores of knowledge and performance. Considering that in the performance part, the scores of the competencybased group is far ahead of the other groups, it demonstrates that, this type of education can have positive outcomes on the clinical practice and performance of nurses.

As per knowledge this is the first report of its kind comparing the results of the two groups and also with the control group. However, in similar studies, it was shown that the results derived from this study are consistent with the results reported by Haghdoost (2009) and Rahmati (2013) on the point that education increases the knowledge and improves the performance of nurses regarding hospital triage $[5,14]$. Also, the study by Yadullahi (2014) had shown that education increases the knowledge and improves the performance of nurses about triage [15]. However, this study differs from the current study regarding these training sessions which were in the form of workshop and training was not performed in the practical method Nevertheless, the results of both studies are consistent. Also, the results of this 
Table 1. Distribution of the research samples based on demographic characteristics

\begin{tabular}{|c|c|c|c|c|c|c|c|c|c|c|}
\hline & & & & & & & & Test S & stic & Prohability \\
\hline Vari & & Cont & Group & & & Comp & $y$-Based & Chi- & rishar & Value \\
\hline & Male & 11 & $44 \%$ & 7 & $28 \%$ & 8 & $32 \%$ & & & \\
\hline Gender & Female & 14 & $56 \%$ & 18 & & 17 & $68 \%$ & 1.531 & - & 0.465 \\
\hline & $<25$ & 5 & $20 \%$ & 5 & $20 \%$ & 6 & $21.3 \%$ & & & \\
\hline Age & $25-31$ & 14 & $56 \%$ & 20 & $80 \%$ & 18 & $69.3 \%$ & & 0.491 & 0.062 \\
\hline & $32-37$ & 6 & $24 \%$ & 0 & $0 \%$ & 1 & $4 \%$ & & & \\
\hline Marital & Single & 9 & $36 \%$ & 11 & $44 \%$ & 9 & $36 \%$ & & & \\
\hline status & Married & 16 & $64 \%$ & 14 & $56 \%$ & 16 & $64 \%$ & & & \\
\hline & Official & 4 & $16 \%$ & 2 & $8 \%$ & 4 & $16 \%$ & & & \\
\hline Employment & $\begin{array}{l}\text { Semi- } \\
\text { official }\end{array}$ & 10 & $40 \%$ & 7 & $28 \%$ & 4 & $16 \%$ & & 5054 & 0.56 \\
\hline & Contractual & 6 & $24 \%$ & 10 & $40 \%$ & 10 & $40 \%$ & & & \\
\hline & Project & 5 & $20 \%$ & 6 & $24 \%$ & 7 & $28 \%$ & & & \\
\hline & $4-1$ & 15 & $60 \%$ & 19 & $76 \%$ & 21 & $84 \%$ & & & \\
\hline Background & $8-5$ & 9 & $36 \%$ & 6 & $24 \%$ & 4 & $16 \%$ & & 4.753 & 0.235 \\
\hline & $12-9$ & 1 & $4 \%$ & 0 & $0 \%$ & 0 & $0 \%$ & & & \\
\hline
\end{tabular}

study are consistent with the study reported by Muhammadnedjad and colleagues (2013) and by Mirhaghi and colleagues (2010) on the point that the knowledge of nurses regarding hospital triage is at a low level [16, 17]. Also, the results derived from this study are consistent with the study by Vahabi and colleagues (2005) in which the two methods of lecture-based training and multimedia training were compared and demonstrated that the knowledge of nurses were increased in both the groups through training [18]. In the studies mentioned above, the number of groups and method of training were different; however, about the results achieved from intervention through training they are consistent with findings of the current study. The only intervention through competency-based training on the ability of nurses in performing resuscitation was carried out by Kavoosi (2013) which led to improvement in the performance of nurses [10]. In the study conducted by Fan on 312 Taiwanese students in two groups of intervention and control it was demonstrated that the competency-based

Table 2. Median and standard deviation of the scores on knowledge received by the emergency ward nurses regarding hospital triage (before and after)

\begin{tabular}{|c|c|c|c|c|c|}
\hline \multirow{2}{*}{$\begin{array}{l}\text { Dependent } \\
\text { Variable }\end{array}$} & \multirow[b]{2}{*}{ Group } & \multicolumn{2}{|c|}{ Before } & \multicolumn{2}{|c|}{ After } \\
\hline & & Median & $\begin{array}{l}\text { Standard } \\
\text { Deviation }\end{array}$ & Median & $\begin{array}{l}\text { Standard } \\
\text { Deviation }\end{array}$ \\
\hline \multirow{4}{*}{$\begin{array}{l}\text { Nurses' knowl- } \\
\text { edge }\end{array}$} & Evidence-based & 6.16 & 1.59 & 6.32 & 1.31 \\
\hline & Lecture intervention & 6.00 & 1.29 & 7.56 & 1.44 \\
\hline & Competency-based intervention & 6.57 & 0.844 & 8.04 & 1.67 \\
\hline & Total & 6.24 & 1.288 & 7.31 & 1.63 \\
\hline
\end{tabular}


Table 3. Median and standard deviation of performance of the emergency ward nurses regarding hospital triage (before and after)

\begin{tabular}{|c|c|c|c|c|c|}
\hline \multirow[b]{2}{*}{ Dependent Variable } & \multirow[b]{2}{*}{ Group } & \multicolumn{2}{|c|}{ Before } & \multicolumn{2}{|c|}{ After } \\
\hline & & Median & $\begin{array}{l}\text { Standard } \\
\text { Deviation }\end{array}$ & Median & $\begin{array}{l}\text { Standard } \\
\text { Deviation }\end{array}$ \\
\hline \multirow{4}{*}{ Nurses' performance } & Evidence-based & 18.50 & 1.02 & 18.00 & 1.29 \\
\hline & Lecture intervention & 18.00 & 1.33 & 26.50 & 0.00 \\
\hline & Competency-based intervention & 18.00 & 1.29 & 33.50 & 0.00 \\
\hline & Total & 18.17 & 1.22 & 22.67 & 6.42 \\
\hline
\end{tabular}

Table 4. Results of one-way analysis of variance for comparing the mean scores of the nurses' knowledge level

\begin{tabular}{|c|c|c|c|c|c|}
\hline Variable & Group & Median & $\begin{array}{l}\text { Standard } \\
\text { Deviation }\end{array}$ & $\mathbf{F}$ & $\mathbf{P}$ \\
\hline \multirow{3}{*}{$\begin{array}{l}\text { Nurses' knowledge } \\
\text { regarding triage }\end{array}$} & Evidence-based & 6.32 & 1.31 & & \\
\hline & Lecture intervention & 7.56 & 1.44 & 8.942 & 0.000 \\
\hline & Competency- based intervention & 8.04 & 1.67 & & \\
\hline
\end{tabular}

Table 5. Tukey post hoc test to examine the significance of the difference between the groups

\begin{tabular}{|c|c|c|c|c|}
\hline \multicolumn{2}{|c|}{ Group } & $\begin{array}{c}\text { Difference of Mean } \\
\text { Scores (i-j) }\end{array}$ & $\begin{array}{c}\text { Standard } \\
\text { Deviation Error }\end{array}$ & Significant Level \\
\hline \multirow{2}{*}{ Evidence-based } & Lecture & $-1.240^{*}$ & 0.42 & 0.012 \\
\hline & Competency-based & $-1.720^{*}$ & 0.42 & 0.000 \\
\hline \multirow{2}{*}{ Lecture intervention } & Evidence-based & $1.240^{*}$ & 0.42 & 0.012 \\
\hline & Competency-based & -0.480 & 0.42 & 0.491 \\
\hline \multirow{2}{*}{ Competency-based } & Evidence-based & $1.720^{*}$ & 0.42 & 0.000 \\
\hline & Lecture & 0.480 & 0.42 & 0.491 \\
\hline
\end{tabular}

Table 6. Comparison of the mean rating of the scores of the performance of the emergency ward nurses regarding triage

\begin{tabular}{|c|c|c|c|c|c|c|}
\hline Variable & Group & Numbers & Mean Ratings & $\mathrm{X}^{2}$ & df & $\mathbf{P}$ \\
\hline & Evidence-based & 25 & 13.00 & & & \\
\hline \multirow[t]{2}{*}{$\begin{array}{l}\text { Nurses' performance } \\
\text { regarding triage }\end{array}$} & Lecture intervention & 25 & 38.00 & 74.000 & 2 & 0.000 \\
\hline & Competency-based intervention & 25 & 63.00 & & & \\
\hline
\end{tabular}


education leads to impressive growth in the intervention group on the academic performance of the students in their courses for internal medicine and surgery, and it is consistent with this study. Fan mentioned that this method of education can reduce the distance between the educational and clinical environments [19].

In another study, competency-based education has led to improvement in the performance as compared with education through traditional classes [20]. Also, in the study conducted by Imamzadeh Ghasemi (2004), it became clear that using performance standards and identifying the weak and strong points and providing guidance feedbacks to nurses will improve the nurses' performance in providing nursing care to patients [21]. These all are consistent with the results achieved from this study about improvement in the performance and function of nurses.

All the above-mentioned studies demonstrate the effectiveness of the educational method studied here and the results achieved from this study also corroborates with it. Numerous studies have been conducted indicating the effectiveness of education on hospital triage. However, nurses are still weak with regard to knowledge and performance which demonstrates that responsible authorities have not paid sufficient attention to the education and training needed in this field whether during the nurses' academic studies or their service and retraining.

\section{Conclusion}

This study demonstarted that both the competencybased educational intervention and lecture lead to an increase in the knowledge and improvement in the performance of nurses about hospital triage. However, the competency-based educational method is more efficient in improving the nurses' performance. Therefore, it is recommended that this educational method should be used for retraining of nurses in the field of triage. It is also recommended that for more generalizability and increasing the capabilities, study should be conducted in critical clinical departments by using the competencybased educational approach as well as its comparison with other educational methods.

Considering the weakness of nurses in patients' triage, it is necessary to repeat and retrain this subject for clinical nurses, and understand that performing this educational method will improve the performance of nursing care and will increase the quality of services provided to patients. It is also recommended that similar study should be conducted in a hospital with a more significant number of participants and to perform similar study with a more extensive follow-up. Furthermore, studies should be conducted with this educational method on variuos other clinical issues in nursing.

\section{Acknowledgements}

This article is based on the MSc. thesis of Seied Davood Hoseini conducted at Department of Nursing, University of Social Welfare and Rehabilitation Sciences of Tehran. The authors of this study wish to express their gratitude to all the nurses of Shahid Motahari, Fatemeh Alzahra, and Rasul-e Akram hospitals and the officials of Gorgan University of Medical Sciences and also the university professors that assisted us in verifying the validity of the tests.

\section{Conflict of Interest}

The authors declared no conflicts of interest.

\section{References}

[1] Faraji A, Khankeh HR, Hosseini MA, Abdi K, Rezasoltani P. Effect of simulated training course on preparedness of nurses to do pre-hospital triage. Journal of Health Promotion Management. 2013; 2(4):24-9.

[2] Azizi F, Hoseini MA, Rahgozar M, Pazooki M. [Triage effect on the length of the waiting period to receive medical services and satisfaction of patients referred to the hospital (Persian)]. Paper presented at The $2^{\text {nd }}$ National Emergency Medicine Conference; 2007 May 27; Tehran, Iran.

[3] Djalali A, Khankeh H, Öhlén G, Castrén M, Kurland L. Facilitators and obstacles in pre-hospital medical response to earthquakes: A qualitative study. Scandinavian Journal of Trauma, Resuscitation and Emergency Medicine. 2011; 19(1):30. doi: 10.1186/1757-7241-19-30

[4] Afzali Moghadam M. [Hospital triage basics (Persian)]. Tehran: Teimourzadeh; 2012.

[5] Taheri N. [Assessment of knowledge and activity of nurses in triage field in hospitals of Kerman University of Medical Sciences, 2005 (Persian)] [PhD dissertation]. Kerman: Kerman University of Medical Sciences; 2005.

[6] Kamrani F, Ghaemipour F, Nikravan M, Alavi Majd H. [Prevalence of miss triage and outcomes under triage of patients in emergency department (Persian)]. Journal of Health Promotion Management. 2013; 2(3):17-23.

[7] Mirhaghi AH, Roudbari M. [A survey on knowledge level of the nurses about hospital triage (Persian)]. Iranian Journal of Critical Care Nursing. 2011; 3(4):167-74.

[8] Tadrisi SD, Siavash Vahabi Y, Ghayem Sh, Ebadi A, Daneshmandi M, Saghafinia M. [Comparing the effect of triage education in lecture and multimedia software on nurses learning 
(Persian)]. Iranian Journal of Critical Care Nursing Spring. 2011; 4(1):7-12.

[9] Rafii F. [Educational leadership and supervision model for Iranian nursing student (Persian)]. Tehran: Iran University of Medical Science. 2002.

[10] Memarian R, Kavosi A, Vanaki Z. The effect of retraining program competency based planning on nurses practice in cardiopulmonary resuscitation in emergency department. Iranian Journal of Nursing Reseach. 2013; 8(3):37-46.

[11] Amouzeshi Z, Mohsenizadeh M, Amouzeshi A. Effect of teaching nursing process using integrated method (Concept map and advance organizer) on nursing students' clinical learning. Future of Medical Education Journal. 2015; 5(1):68-71.

[12] Wong S. Nurse-teacher behaviours in the dinicai fieid: Apparent effect on nursing students' learning. Journal of Advanced Nursing. 1978; 3(4):369-72. doi: 10.1111/j.13652648.1978.tb00852.x

[13] Marzuki MA, Hassan H, Wichaikhum O, Nantsupawat $\mathrm{R}$. Continuing nursing education: Best practice initiative in nursing practice environment. Procedia - Social and Behavioral Sciences. 2012; 60:450-5. doi: 10.1016/j.sbspro.2012.09.405

[14] Rahmati H, Azmoon M, Meibodi MK, Zare N. Effects of triage education on knowledge, practice and qualitative index of emergency room staff: A quasi-interventional study. Bulletin of Emergency \& Trauma. 2013; 1(2):69-75. PMCID: PMC4771226

[15] Kalantarimeibidi M, Yadollahi A, Esfandiari S. The effect of education on the knowledge and practice of emergency department's nurses regarding the patients' triage. Tibb-i urzhāns-i İrān. 2014; 1(1):40-4.

[16] Tabatabai A, Mohammadnejad E, Salari A. Nursing students' awareness of triage in the emergency ward. Jorjani Biomedicine Journal. 2013; 1(1):30-4.

[17] Mirhaghi AH, Roudbari M. A survey on knowledge level of the nurses about hospital triage. Iranian Journal of Critical Care Nursing. 2010; 3(4):167-74.

[18] Asgari F, Mahjoub H, Jamali M, Khanjani H, Vahabi SR, Amani $\mathrm{M}$, et al. The patient service quality in the emergency departments. Journal of Health Administration. 2005; 7(18):30-6.

[19] Fan JY, Wang YH, Chao LF, Jane S-W, Hsu LL. Performance evaluation of nursing students following competencybased education. Nurse Education Today. 2015; 35(1):97-103. doi: 10.1016/j.nedt.2014.07.002

[20] Gravina EW. Competency-based education and its effect on nursing education: A literature review. Teaching and Learning in Nursing. 2017; 12(2):117-21. doi: 10.1016/j. teln.2016.11.004

[21] Emamzadeh Ghasemi H, Vanaki Z, Memarian R. The effect of using "applied in-Service education model" on quality of nursing care in surgery unit. Iranian Journal of Medical Education. 2004; 4(2):13-21. 
